\title{
Requirement Analysis of Security CT Center After-sales Service System Yongchang Ren ${ }^{\mathrm{a}}$, Yongzhe $\mathrm{Ma}^{\mathrm{b}}$, Chengwei $\mathrm{Wu}^{\mathrm{c}}$ \\ School of Information Science and Technology, Bohai University, Jinzhou, 121013, China \\ a1213552916@qq.com, b1125444268@qq.com, ‘357889057@qq.com
}

Keywords: after-sales service; requirement analysis; user analysis; business requirements; functional requirements; non-functional requirements

\begin{abstract}
Detailed requirements analysis can ensure that the system meets the customers' actual requirements. This paper carries out researches based on the actual workflow of security equipment after-sale service, constantly communicate with customers to analyze the actual needs of the system, make sure that the user requirements, business requirements, functional requirements and non-functional requirements which customers' needs on system, the main work is to confirm the actual requirements of various aspects of user roles and authority, business module and workflow, system module division and realization function, system scalability, stability, security and performance and so on, the focus is on data security requirements, forming the requirements document. Conducive to determine system development tasks, reasonable design system, provide customers with solutions, provide an important reference basis for software development and acceptance in the late.
\end{abstract}

\section{Introduction}

Along with social development and the trend of market globalization, the proportion after-sale service income occupies is higher and higher, which is converting from daily maintenance work to the value-added service that provides customers with diversity [1]. At present, security equipment after-sales service exits many problems such as low customer satisfaction, poor information sharing degree, lack of systematic and scientific management and so on, it is imminent to achieve information construction of after-sales service. As the first step in the software development design, requirement analysis is the foundation of successful implementation of after-sales service without papers [2]. This paper makes requirement analysis on the present situation and workflow to understand customer needs, further develop the details of the software development, explain system data requirements, functional requirements and performance requirements, clearly identify the implementation process of each function [3]. Carrying out mainly from four aspects of the user needs, business requirements, functional requirements and non-functional requirements to provide customers with solutions or the required conditions or power achieve targets, which makes every effort to achieve consensus between customers and software developers in aspects such as system function design and implementation details, in order to better guide the each work of software development [4], reduce unnecessary trouble for subsequent system development and maintenance.

\section{System Requirements}

System requirement is the starting point of requirement analysis, which mainly includes three stages. The first stage, determine the purpose of building system and the target of achieving user expectations; the second stage, system function model is initially determined; the third stage, clear and definite system user roles and authority. In the three stages, the most important is the last two stages, while design system in the late, which needs to design function according to the divided system module, control data interaction through setting the user authority. The three stages are described in detail as follows.

The first stage, the purpose and target of system. Starting from the actual demands of security equipment after-sales service, making analysis on the demand of the equipment maintenance process management and spare parts management, which realizes the information, scientific and 
systematic of after-sales service management [5]. Among them, equipment maintenance process management is to cooperate with the work process flow of security CT center equipment maintenance, realize the standardization of security CT center equipment maintenance work. Through standardization reduce information transmission errors, maintenance work delay which man-made factors lead, improve equipment maintenance work efficiency (maintenance response time, customer complaint rate). Through recording maintenance work process, which traces back the follow-up maintenance work, provides the basis for maintenance work assessment, realizes the recording, processing and tracking of maintenance work orders, tasks and record sheets.

Spare parts management is to establish the database of basic files of security CT products maintenance spare parts library, on the basis gradual implementation of spare parts application, all kinds of spare parts consumption, spare parts repair, spare parts scrap and other related management process, which lays the foundation for refinement, scientific management of managing maintenance spare parts, achieves security CT products maintenance spare parts inventory management, spare parts maintenance consumption records which are combined with maintenance work, spare parts application, spare parts requests, spare parts storage, spare parts allocation, the tracking of spare parts scrap record, rework spare parts application, storage, rework parts scrap, the tracking of rework parts repair record.

The second stage, system function module. Equipment repair and maintenance are the main modules, which relates to device adjustment, spare parts application, spare parts outbound and storage, spare parts inventory information management and basic data management, shown in Fig.1.

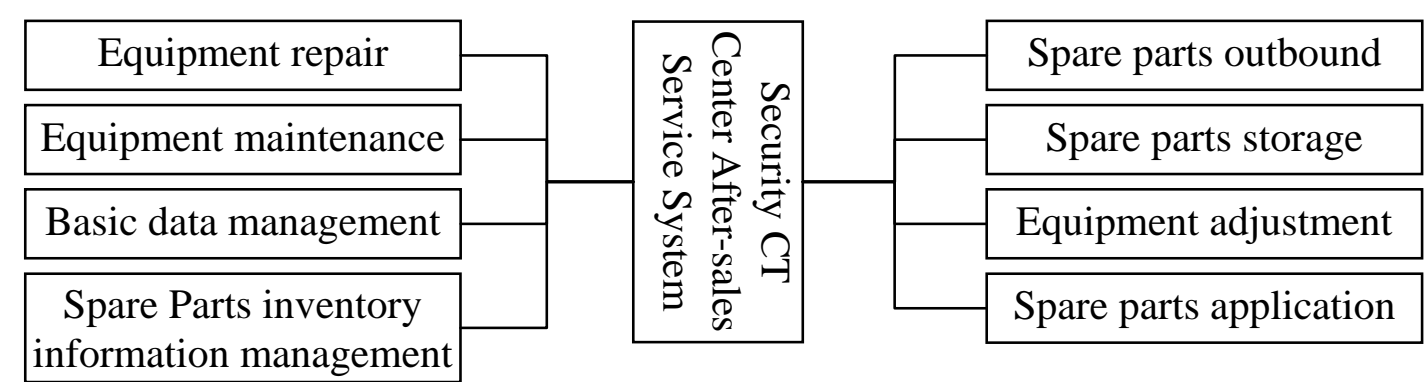

Fig. 1. System function module

The third stage, user roles and permissions. Because equipment after-sales service workflow is very complex, the links of repair, maintenance, spare parts outbound and storage all require multi-level approval, and many people own the same position, in practical work, mainly through the offline communication. In order to realize the human and scientific management, according to the user roles setting the appropriate permissions, the same role has different system accounts, when in the approval of the information sheet, can only approval the list belongs to the account, which effectively avoids data loss and leak, data security is effectively guaranteed.

\section{Business Requirements}

As the most important part of requirements analysis, business requirements represent clients' highest level of target requirements on system, which is often the demand of the strategic level, the initial impetus for developing systems [6]. Based on the functional modules analysis of system requirements analysis, combined with the actual working condition, business analysis of security equipment after-sales service system that this paper builds includes maintenance management, application management, outbound management, return management, storage management and basic data approval. Among them, maintenance management relates to equipment maintenance process management; application management involves stock, spare parts, safety spare parts and other kinds of spare parts application process management; outbound management involves spare parts, safety spare parts and other kinds of spare parts outbound process management; return management involves spare parts, safety spare parts and other kinds of parts spare return process management; inventory management involves repair, failure, investigation and other kinds of spare 
parts inventory process management; basic data approval involves equipment basic information and safety information approval process management. This paper mainly describes the business requirements of equipment maintenance process managements, the workflow is shown in Fig. 2.

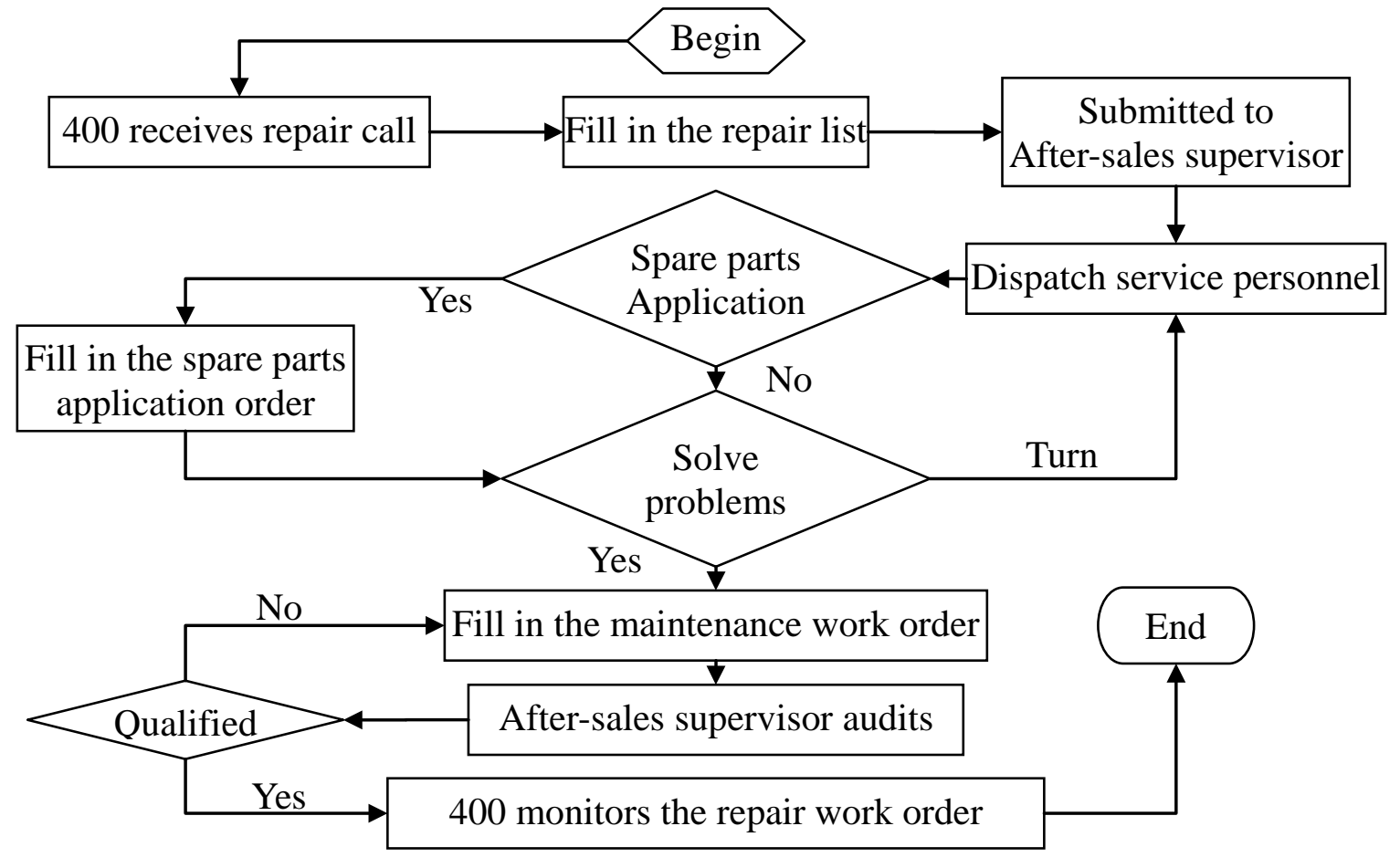

Fig. 2. Equipment maintenance workflow chart

A detailed description is as follows:

First, 400 call center receives customer service telephone, records, logins system, fills the relevant information of required repair equipment.

Second, submitted to the service supervisor, service supervisor through offline negotiates with business representatives, deals with the documents not in the warranty period, if business representatives are unable to communicate with customers, service supervisor can close the document; if the communication is complete, service supervisor can fill maintenance form.

Third, service supervisor receives maintenance list, according to the condition of maintenance list, who can turn off the maintenance list, can also assign specific maintenance personnel to repair.

Fourth, equipment maintenance personnel receives the maintenance list of service supervisor to complete the equipment maintenance tasks, if cannot qualified for this maintenance task, can coordinate with other engineers, and transfer the maintenance list to them, the engineers that receive transfer maintenance list need to do confirm operations on this maintenance list, the maintenance order can be accepted.

Fifth, equipment maintenance personnel repairs equipment, and fill the repair work orders, submit to maintenance supervisor arranges the maintenance list to approval, if there is a spare parts application process, maintenance personnel also need to submit a spare parts return application form, the two processes in the approval process comply with the following rules: when the maintenance work orders pass the audit, spare parts return application forms pass audit automatically; if not pass, spare parts to return the application is automatically dismissed.

Sixth, service supervisor receives the maintenance staff maintenance personnel submits, which is audit, if not passed, then returned to maintenance personnel to submit one more time; If approved, then submitted to the 400 call center to confirm.

Seventh, 400 call center receives maintenance list and communicates with customers, whether equipment maintenance has been repaired, and spare parts has done returned applications. If maintenance is good and related spare parts are returned, then maintenance list is closed, if any item is not completed, then the repair list will not be closed. 


\section{Functional Requirements}

Functional requirements are based on business requirements, which explain the system function developers need to implement [7]. Under normal circumstances, in order to meet a specific business requirement, the system function is subdivided into multiple modules, collaborative completion. All system workflow begin at the point that the 400 customer service receives repair tasks, this article mainly expounds functional requirements of repair and maintenance work orders management and matters needing attention.

Repair work orders management:

Main users: 400 call center customer service, maintenance personnel, service supervisor, Business representatives.

Description: 400 call center customer services are responsible for building and closing maintenance work orders, service supervisor and business representatives audit maintenance work orders, maintenance personnel repairs according to the maintenance work order.

Function operations:

[New] Pop-up new repair work orders form. [Save] Save new repair work orders form information, the state of the form is draft. [Delete] Delete new repair work order form information, only the draft state form can be deleted. [Submit] Repair work orders are submitted to business representative to audit, and then submitted to service supervisor. [Query] Query maintenance work order information according to the condition. [Abolish] Abolish maintenance work orders. [Close] Close this form. Functional authority contrast table is shown as follows:

Business rules:

First, 400 call center customer services receive a repair telephone, fill form records, for uncommitted maintenance work orders, customer service can delete and edit again, and for submitted work orders, can be regressed and closed only by a superior, but cannot be deleted.

Second, maintenance personnel transfers maintenance work orders which needs another maintenance personnel to receive, for received maintenance work orders, the maintenance personnel cannot look over again.

Third, maintenance work orders in warranty period are submitted to service supervisor to audit, others can only be submitted to business representative to audit, and then to service supervisor.

Fourth, business representatives, service supervisor and maintenance personnel can see only their own assigned maintenance work orders.

\section{Non-functional Requirements}

Non-functional requirements refer to meet the requirements expect that customers' specific requirements on business and software functions [8], this article makes non-functional requirements researches from the system scalability, stability, security and performance and other aspects, in order to satisfy customers requirements in all aspects, decrease late system modification and maintenance. Specific requirements are as follows:

Scalability: can at any time make transformation and upgrading according to the changes of business requirements.

Stability: real-time monitoring data, when the number of users is large, the system will not appear paralyzed; with a certain fault tolerance, in the wrong time, automatically record the reasons for the error and recovery.

Usability: the realization of compatible with most browsers, users can input URL to access to the system through the browser, without the need to install the client.

Security: the same role can correspond to multiple user accounts, but the leading role can only have a user account; only the leading role can make functional authorizations for system users, which sets permissions; different roles and users carry out their own respective functions, and obtain data, mutual interference.

Friendly: the system interface is simple, the operation mode is simple; provide prompt information, which can realize the interactive mode such as mouse drag and drop, keyboard 
commands and so on.

Standard: system operation process should be consistent with the enterprise internal work processes. In addition, the system should deal with a lot of batch work orders in a short period of time, at the same time, the response time of approving and transferring work orders, making basic operations on data should be completed within a few seconds.

\section{Conclusion}

Requirement analysis is to clear and definite customers' actual demands, this article makes requirement analysis on security equipment after-sales service from four aspects of the user needs, business requirements, functional requirements and non-functional requirements, the purpose is to avoid that constant demand changes bring unnecessary trouble to system development. User needs confirm user roles and authorities, business requirements confirm business module and workflow, functional requirements confirm system module division and implementation functions, non-functional requirements confirm the actual requirements users make on the aspects of system scalability, stability, security and performance and so on, the focus is to make sure data security requirements [9]. Eliminate the understanding differences between developers and customers, identify system development tasks, guarantee that system meets the actual demands [10].

\section{Acknowledgement}

This work is supported by social science fund project of Liaoning province (L13DTQ01).

\section{References}

[1] S. F. Yin, "Research of Engine Service Management Platform," Manufacturing Automation, vol. 33, no. 9, pp. 21-23, 2011.

[2] H. Hui, L. Ma, "Requirements Analysis Based on UML Online Examination System," Computer Knowledge and Technology, vol. 29, no. 6, pp. 8400-8401, 2010.

[3] G. C. Zhen, W. W. Yang, "Global Collaboration Requirement Analysis System in Cloud Computing," Procedia Computer Science, vol. 62, no. 1, pp. 332-334, 2015.

[4] C. H. Yu, X. Zhao, J. J. Li. L. Wang, "Requirements Analysis Design Based on UML Line Management System," Journal of Sichuan Ordnance, vol. 35, no. 9, pp. 114-117, 2014.

[5] Uwe Dombrowski, Christian Engel, "Impact of Electric Mobility on the after Sales Service in the Automotive Industry," Product Services Systems and Value Creation. Proceedings of the 6th CIRP Conference on Industrial Product-Service Systems, vol. 16, no. 1, pp. 152-157, 2014.

[6] L. F. Liu, "Requirements Analysis Research of VIBE System," Master's Degree of Beijing University of Posts and Telecommunications, 2012.

[7] David K. H. Chua, T. Q. Nguyen, K. W. Yeoh. Automated Construction Sequencing and Scheduling from Functional Requirements, Automation in Construction, vol. 35, no. 1, pp. 79-88, 2013.

[8] M. Liu, "Requirements Analysis Research of JN City Housing Information Systems Project," Master's Degree of Shandong University, 2014.

[9] C. Y. Huang, "Requirements Analysis and Architecture Design of Abnormal Test System for Malicious Code," Master's Degree of Yunnan University, 2013.

[10] P. Du, "Requirement Analysis and Designing of Library Management System on the Basis of JSP," Master's Degree of Shandong University, 2010. 